OAK RIDGE

NATIONAL LABORATORY

MANAGED BY UT-BATTELLE

FOR THE DEPARTMENT OF ENERGY

Development of Spheroidal Inorganic Sorbents for

Treatment of Acidic Salt-Bearing Liquid Waste

\author{
J. L. Collins \\ K. K. Anderson
}




\section{DOCUMENT AVAILABILITY}

Reports produced after January 1,1996, are generally available free via the U.S. Department of Energy (DOE) Information Bridge:

\section{Web site: http://www.osti.gov/bridge}

Reports produced before January 1,1996 , may be purchased by members of the public from the following source:

National Technical Information Service

5285 Port Royal Road

Springfield, VA 22161

Telephone: 703-605-6000 (I-800-553-6847)

TDD: $703-487-4639$

Fax: 703-605-6900

E-mail: info@ntis.fedworld.gov

Web site: http://www.ntis.gov/support/ordernowabout.htm

Reports are available to DOE employees, DOE contractors, Energy Technology Data Exchange (ETDE) representatives, and International Nuclear Information System (INIS) representatives from the following source:

Office of Scientific and Technical Information

P.O. Box 62

Oak Ridge, TN 37831

Telephone: 865-576-8401

Fax: 865-576-5728

E-mail: reports@adonis.osti.gov

Web site: http:///www.osti.gov/contact.html

This report was prepared as an account of work sponsored by an agency of the United States Government. Neither the United States government nor any agency thereof, nor any of their employees, makes any warranty, express or implied, or assumes any legal liability or responsibility for the accuracy, completeness, or usefulness of any information, apparatus, product, or process disclosed, or represents that its use would not infringe privately owned rights. Reference herein to any specific commercial product, process, or service by trade name, trademark, manufacturer, or otherwise, does not necessarily constitute or imply its endorsement, recommendation, or favoring by the United States Government or any agency thereof. The views and opinions of authors expressed herein do not necessarily state or reflect those of the United States Government or any agency thereof. 
ORNL/TM-2000/367

Chemical Technology Division

\title{
Development of Spheroidal Inorganic Sorbents for Treatment of Acidic Salt-Bearing Liquid Waste
}

\author{
J. L. Collins \\ K. K. Anderson
}

Date Published: August 2001

Prepared for the

U.S. Department of Energy, Office of Science and Technology

Efficient Separations and Processing Crosscutting Program

Prepared by the

OAK RIDGE NATIONAL LABORATORY

Oak Ridge, Tennessee 3783 1-6285

managed by

UT-BATTELLE, LLC

for the

U.S. DEPARTMENT OF ENERGY under contract DE-AC05-00OR22725 


\section{CONTENTS}

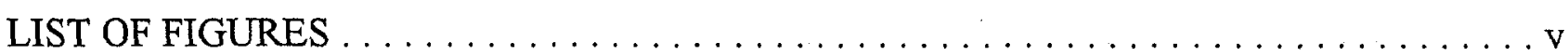

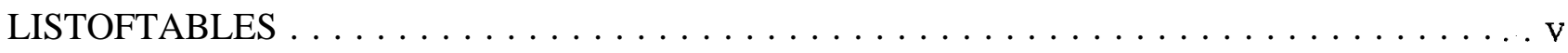

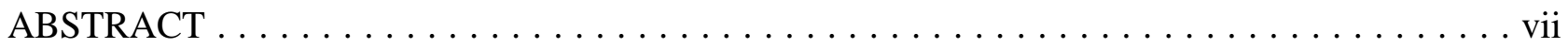

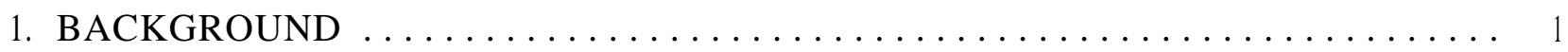

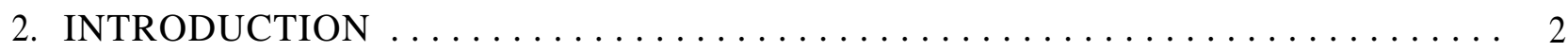

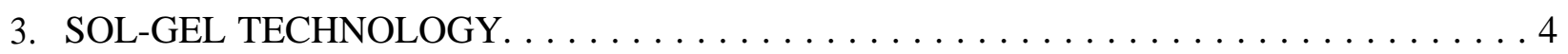

4. CHEMICAL FLOW SHEET AND APPARATUS $\ldots \ldots \ldots \ldots \ldots \ldots$

5. CHEMISTRY OF THE HMTA INTERNAL GELATION PROCESS . . . . 8

6. DEVELOPMENT OF ZrHP-AMP SPHEROIDAL SORBENT $\ldots \ldots \ldots \ldots \ldots \ldots \ldots 12$

6.1 AMMONIUM MOLYBDOPHOSPHATE .................... 12

6.2 ZIRCONIUM MONOHYDROGEN PHOSPHATE ................ 13

6.3 DEVELOPMENT AND PREPARATION OF ZrHP-AMP COMPOSITE MICROSPHERES ........................... 13

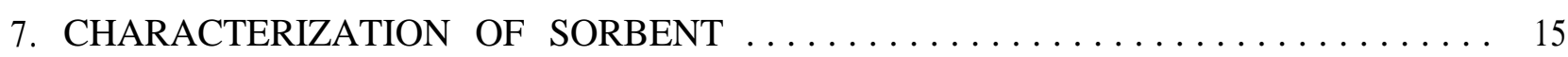

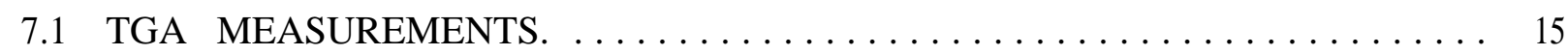

7.2 CRUSH STRENGTH MEASUREMENTS $\ldots \ldots \ldots \ldots \ldots \ldots \ldots \ldots \ldots \ldots$

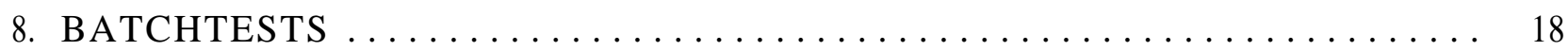

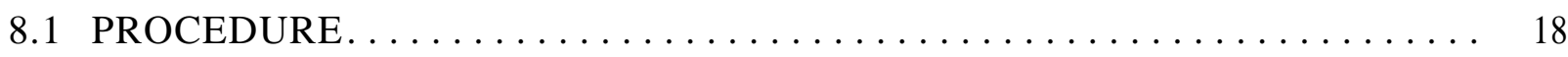

8.2 CALCULATIONS . . . . . . . . . . . . . . . . . . . . . . 19

8.3 COMPARATIVE CESIUM REMOVAL BATCH TEST RESULTS. .......... 19

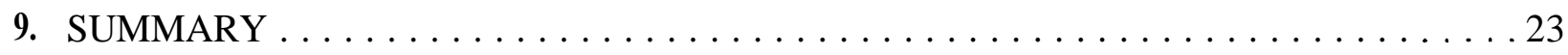

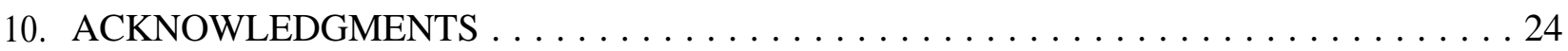

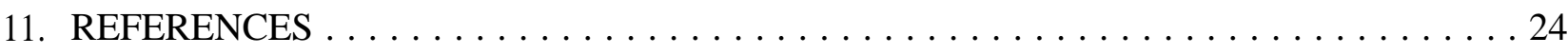


$=$ 


\section{LIST OF FIGURES}

Figure

Page

1 Laboratory-scale system for forming monodispersed microspheres with

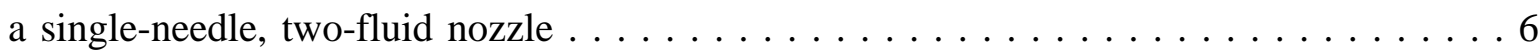

2 Schematic of the laboratory-scale system for preparing microspheres with a

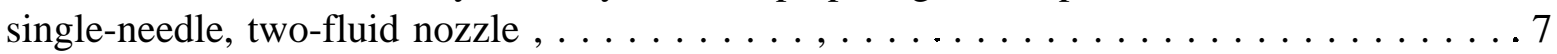

3 Laboratory-scale system for forming monodispersed microspheres with a

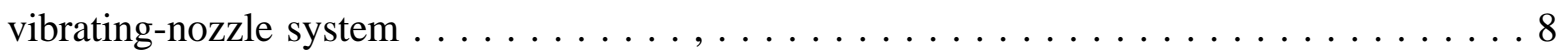

4 Schematic of single-fluid pulsed tubular nozzles used to increase the production

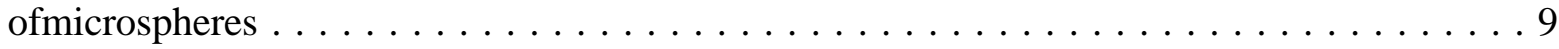

5 Internal gelation flow sheet for making AMP-ZrHP microspheres $\ldots \ldots \ldots \ldots$

6 Weight loss from samples of ZrHP microspheres, PHOZIR A, and components of the internal gelation process by TGA in $100 \%$ nitrogen $\ldots \ldots \ldots \ldots$

7 Weight loss from samples of ZrHP microspheres, PHOZIR A, and components of the internal gelation process by TGA in $100 \%$ oxygen $\ldots \ldots \ldots \ldots \ldots \ldots$

\section{LIST OF TABLES}

Table

1 Dynamometric measurement of microspheres (crush strength in grams) . . . . . . . 17

2 Analytical data for MVST W-27 supernatant and acidified MVST W-27

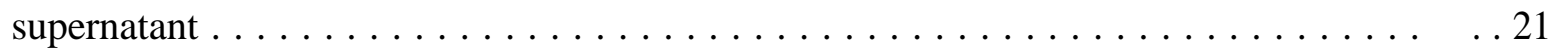

3 Removal of cesium from acidified MVST W-27 supernatant $\left(0.16 \mathrm{~A} 4 \mathrm{H}^{+}\right) \ldots . .22$

4 Removal of cesium from acidified MVST W-27 supernatant $\left(1.8 \mathrm{MH}^{\prime}\right) \ldots \ldots \ldots$ 


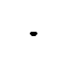




\begin{abstract}
A B S T R A C T
A spheroidal composite inorganic sorbent was developed for U.S. Department of EnergyEfficient Separations and Processing Crosscutting Program (USDOE-ESP) for potential use in removing radioactive cesium isotopes from acidic high-salt waste streams such as those at Idaho National Engineering and Environmental Laboratory (INEEL). The sorbent, zirconium monohydrogen phosphate (ZrHP) embedded with fine powder of ammonium molybdophosphate (AMP), was prepared using a unique internal gelation process which can be used to make porous reproducible microspheres that are structurally strong, have a low tendency for surface erosion, and improve the flow dynamics for column operations. Both $\mathrm{ZrHP}$ and AMP are excellent sorbent materials and, being inorganic, are stable in high radiation fields. AMP is a very effective sorbent for removing cesium from salt-bearing waste streams for a wide range of acidity. In the $\mathrm{pH}$ range of 2 to $10, \mathrm{ZrHP}$ is also a very effective sorbent for removing $\mathrm{Cs}, \mathrm{Sr}, \mathrm{Th}, \mathrm{U}(\mathrm{VI}), \mathrm{Pu}(\mathrm{IV}), \mathrm{Am}(\mathrm{III}), \mathrm{Hg}$, and $\mathrm{Pb}$ from streams of lower ionic concentrations.

Crucial to developing the spheroidal AMP-ZrHP sorbent was to determine the ideal weight percentage of AMP that could be embedded in the ZrHP microspheres in order to maintain the structural integrity of the microspheres and also achieve a good cesium separation. A total of 12 preparations were made. The dry weight percentage of AMP ranged from 30 to 60 . Overall, the best composite microspheres prepared contained 50\% AMP (by dry weight measurement). Another composite microsphere, which was composed of titanium monohydrogen phosphate (TiHP) embedded with 18 wt \% (air-dried weight) potassium cobalt hexacyanoferrate (KCoCF) and developed for a different separations application, was also batch tested for comparison. It proved to be as effective in removing the cesium as the air-dried AMP (50 wt \%)-ZrHP. Granular $\mathrm{KCoCF}$ was also prepared and was very effective. Large samples of each of these materials were sent to INEEL for small-column testing with real waste.

Cesium removal batch tests were conducted with Melton Valley Storage Tank W-27 supernatant that was acidified to $1.8 \mathrm{~A} 4$ free acid to simulate the acidic high-salt waste at INEEL. A 200: 1 supernatant $(\mathrm{mL})$ to sorbent $(\mathrm{g})$ ratio was used. The air-dried AMP (50 wt \%)-ZrHP microspheres were effective in removing the cesium. A cesium distribution ratio $\left(\mathrm{D}_{\mathrm{Cs}}\right)$ of $980 \mathrm{~mL} / \mathrm{g}$ was obtained, removing $82.5 \%$ of the cesium. For comparison, similar batch tests were also conducted with AMP-1 powder (Bio-Rad Laboratories); a $D_{C s}$ of $1382 \mathrm{mg} / \mathrm{L}$ was obtained, removing $86.8 \%$ of the cesium.
\end{abstract}





\section{1 . BACKGROUND}

For almost three decades until 1992, Idaho National Engineering and Environmental Laboratory (INEEL) reprocessed a variety of nuclear fuels primarily for the recovery of uranium-235.' Highlevel salt-bearing acidic liquid waste from these activities was stored in underground stainless steel tanks which were enclosed in concrete vaults, Most of this high-level waste was calcined by 1998; however, an'inventory of liquid waste remains which includes other sodium-bearing waste streams that were added from site decontamination and decommissioning activities. This waste is now considered to be a mixed transuranic waste rather than high-level waste (HLW), but because of the large volume and radioactivity, it is being treated as if it were HLW. As of August 1998, there was about $5000 \mathrm{~m}^{3}$ (1.3 million gallons) of liquid waste in about half of the 11 underground tanks. Since these tanks do not have secondary containment liners that meet the current regulatory requirements of the Resource Conservation and Recovery Act (RCRA), they cannot be used for long-term storage. The DOE Office of Environmental Management is developing an Environmental Impact Statement that addresses options for converting INEEL's high-level and salt-bearing wastes into waste forms that are suitable for interim on-site storage and for eventual transport and disposal in repositories or other facilities.

Segregation of the high- and low-activity fractions is one of the process steps currently being considered by the INEEL HLW program. In addition, several options are being considered for processing INEEL's calcines and liquid waste into other forms. One approach is to dissolve the

calcine into aqueous-based solutions; separate the ${ }^{137} \mathrm{Cs},{ }^{90} \mathrm{Sr}$, and actinides; convert the remaining large volume of liquid into low-level grout; and solidify the high-level fraction in a glass or cement waste form. Options for removing cesium from acidic salt-bearing solutions involve either ion exchange or coprecipitation. A multistage continuous process using ion-exchange columns would be advantageous because considerably less sorbent would be needed for the required cesium separation.'

Using the ion-exchange separation, only a few sorbents are known to be'effective in removing cesium from acidic salt-bearing waste: ammonium molybdophosphate (AMP) $\left[\left(\mathrm{NH}_{4}\right)_{3} \mathrm{PO}_{4} \cdot 12 \mathrm{MoO}_{3} \cdot \mathrm{H}_{2} \mathrm{O}\right]$; potassium or sodium salts. of hexacyanoferrates(II) $\left(\mathrm{Cu}^{2+}, \mathrm{Ni}^{2+}\right.$, and $\mathrm{Co}$ ") of transition metals $\left[\mathrm{Na}\right.$ or $\left.\mathrm{K}_{1.0} \mathrm{Me}_{1.5}(\mathrm{CN})_{6}\right]$; sodium phosphotungstic acid $\left(\mathrm{Na}_{3}\left[\mathrm{P}\left(\mathrm{W}_{3} \mathrm{O}_{10}\right)\right] \cdot 24 \mathrm{H}_{2} \mathrm{O}\right)$; and IONSIV ${ }^{\mathbb{1}} \mathrm{IE}-911^{2-7}$ Of these sorbents, IONSIV ${ }^{\circledR} \mathrm{IE}-911$ is the only one that has been 
commercialized (by. Universal Oil Products). ${ }^{2-5}$ It is a granular engineered form in which a proprietary inorganic matrix material is embedded with crystalline silicotitanate (CST) that was developed by Sandia National Laboratory.

The current reference sorbent for potential treatment of the INEEL waste is the composite sorbent AMP-PAN (polyacrylonitrile) which is composed of tine particles of AMP (-1 $\mu \mathrm{m})$ imbedded in a binding polymer of polyacrylonitrile. It was prepared and supplied by the Czech Technical University, Prague. ${ }^{5}$ FS-2, a Russian-prepared potassium copper hexacyanoferrate granulated with silica binder, also proved to be very effective in removing cesium. ${ }^{6-7}$ Like AMP, the hexacyanoferrates are fine particles and have to be bound in another material to be used in column operations. The advantage of AMP and hexacyanoferrates is that cesium can be eluted from either of these materials. However, neither FS-2 nor AMP-PAN has been commercialized yet, and their availability is uncertain.' If AMP-PAN were to be used, issues concerning the potential degradation and flammability of the PAN binder would have to be addressed.'

IONSIV ${ }^{\circledR}$ IE-911 was also tested at INEEL, and the loading capacity was found to be about two times less than that of FS-2 and AMP-PAN. Cesium could not be eluted from the IONSIV ${ }^{\circledR}$ IE-911. The long-term insolubility of the CST and its binder in flowing acidic salt-bearing waste is not known and would need to be determined.

\section{INTRODUCTION}

The primary objective of this USDOE-ESP task was to develop, prepare, and test composite spheroidal inorganic ion-exchange sorbents for potential use in removing radioactive cesium isotopes from acidic high-salt waste streams such as those at INEEL. AMP was the active sorbent selected for the task because of its high selectivity and loading capacity for cesium. Zirconium monohydrogen phosphate (ZrHP) was chosen as the spheroidal matrix material used to homogeneously embed fine AMP powder. In the $\mathrm{pH}$ range of 2 to $10, \mathrm{ZrHP}$ is also a very effective sorbent for removing $\mathrm{Cs}, \mathrm{Sr}$, Th, U(VI), $\mathrm{Pu}(\mathrm{IV}), \mathrm{Am}(\mathrm{III}), \mathrm{Hg}$, and $\mathrm{Pb}$ from streams of lower ionic concentrations.

Inorganic sorbents are commercially available only as tine powders or as unstable granular particles that are not readily adaptable to continuous processing such as column chromatography. AMP has a microcrystalline structure that does not lend itself to large particle preparations in pure 
form. Typically its particle size is in the range of 1 to $5 \mu \mathrm{m} .{ }^{8-12}$ For AMP to be used in column operations, it has to be prepared as a composite sorbent in which it is embedded in a matrix material that can be sized to provide good flow dynamics (200 to $900 \mu \mathrm{m})$. Smaller-sized particles provide the best loading kinetics. A particle size in the range of 300 to $600 \mu \mathrm{m}$ is more ideal. Silica gel$\operatorname{AMP}(65 \mathrm{wt} \%)^{13}$ and AMP (85 wt \%)-PAN ${ }^{5,14}$ composites were prepared and column tested. The percentages of AMP were based upon the dry weight of the sorbents. Neither sorbent is currently commercially available. Cesium loading column studies that were conducted with AMP-PAN at INEEL showed that AMP (as powder) has a very high loading capacity for cesium with rapid sorption kinetics.' However, issues regarding the potential degradation and flammability of the polyacrylonitrile binder when exposed to high ionizing radiation fields' remain to be addressed. The thermal instability of the binder during hypothetical off-normal column operating events is also a source of concern, considering $1 \mathrm{~g}$ of ${ }^{137} \mathrm{Cs}$ can generate about $0.45 \mathrm{~W}$. Column studies by Faubel and Ali showed that AMP performed very well with acidic high-salt loadings with a breakthrough capacity of $60 \mathrm{~g} / \mathrm{kg}^{2}$

Preparation of inorganic ion exchangers as microspheres satisfies the criteria of providing radiation and thermal stability. Microspheres made using the internal gelation process are perfect spheres which provide ideal flow dynamics for column operations. In addition to being able to control the size of the microspheres, the microstructure (density and porosity) of the microspheres in some cases can be tailored by varying the chemical and physical process parameters. This allows some control over the selectivity and loading behavior of the exchanger. One of the key factors in synthesizing microspherical sorbents that are structurally strong with a'low tendency for surface erosion is the determination of the optimum broth formulations and process conditions.

ZrHP-AMP microspheres could possibly be used as a final waste form. Once loaded with cesium, they could be dried to remove any occluded water or water of hydration and densified into ceramic spheres by heating them to temperatures $2450^{\circ} \mathrm{C}$. Densitication entraps ions that are sorbed within the matrices of the ceramic spheres, as demonstrated in the case of the Synroc process." The crystalline ceramic spheres should also have excellent resistance to leaching of the entrapped cesium. In addition, the dried cesium-loaded microspheres can probably be incorporated into other inorganic waste forms such as glass, grouts, or ceramics.

The hexamethylenetetramine (HMTA) internal gelation process of making inorganic ion exchangers as microspheres is amenable to commercialization. The large-scale engineering of the 
process has already been developed at ORNL for nuclear fuels. The same equipment designs with minor modifications could be used to make commercial quantities of the microspheres. An economic evaluation of this process for the production of sorbents and for other uses has been reported by Collins and Watson."

\section{SOL-GEL TECHNOLOGY}

There are a number of gel-forming processes used in the preparation of inorganic sorbents, catalysts, and ceramics. ${ }^{16,17}$ A common requirement of all of these processes is that the constituents of the processes be suitable for the bonding of colloidal particles into gel structures, The gels usually are hydrous metal oxides. These processes are generally identified as "sol-gel" processes, and the chemistries are complex and path dependent. Typically, they 'are defined as external or internal gelation processes. For external gelation processes, the gelation reactions involve mass transfer to a second phase or fluid. By comparison, there is little or no mass transfer in the internal gelation processes. One of the original external gelation processes for the preparation of nuclear fuels was developed at ORNL. ${ }^{16,18}$ It was based on the gelation of colloidal sol droplets by extracting the water from them while they were suspended in an immiscible alcohol. In other external gelation processes that were developed worldwide at various laboratories, droplets of organic polymer solutions or sols were chemically gelled with ammonia, usually by mass transfer of the ammonia from a surrounding gas or solution. ${ }^{19}$

Making silica-alumina gel as spheres was one of the more interesting internal gelation processes. ${ }^{16,17} \mathrm{Gel}$ spheres were made by continuously mixing an acid solution of $\mathrm{AlCl}_{3}$ or $\mathrm{Al}_{2}\left(\mathrm{SO}_{4}\right)_{3}$ with sodium silicate as it dropped into an immiscible organic medium. The aqueous droplets gelled while in the organic medium. The key to this process is the slow or delayed gelation of silica when the sodium silicate is acidified.

The most widely studied internal gelation processes in recent years involve the water hydrolysis of metal alkoxides. ${ }^{20}$ In these processes, solution temperature and $\mathrm{pH}$ are key parameters used in controlling hydrolysis and polymerization. The commercial sodium titanate and silicotitanate sorbents are made using metal alkoxide processes followed by hydrothermal treatment. ${ }^{21,22}$ Materials made by this method are fine powders, and engineered forms are made by the granulation of these materials using binders. 
The HMTA internal gelation method ${ }^{23}$ employed in this task also provides a unique means of making hydrous metal oxide gel spheres; however, the method is very different from the one described above to make silica-alumina gel spheres. The HMTA internal gelation method is similar to the method that was used to develop light-water and breeder reactor microspheroidal fuels at $\mathrm{ORNL}^{24,25}$ and other laboratories worldwide. As in those earlier preparations, an organic base (HMTA) and a complexing agent (urea) are used in combination with metal salts in the broth formulations. The key to making hydrous metal oxide microspheres lies in determining the critical broth formulations and the gel-forming operating parameters, which have been found to be uniquely different for each of the hydrous metal oxides that have been prepared. The HMTA internal gelation was first used by M.E.A. Hermans et al. at Keuring van Electrotechnische Materialen at Arnhem (KEMA) in the Netherlands for making microspheroidal uranium oxide nuclear fuel. ${ }^{23}$ Later the HMTA internal gelation process was extensively developed at ORNL and other laboratories worldwide for making fuels of uranium, plutonium, and thorium and mixtures of these elements for fast breeder reactors, high-temperature gas-cooled reactors, and light-water reactors.

Microspheres of any specific size in a diameter range of 0.1 to $2 \mathrm{~mm}$ can be reproducibly made with apparatuses that were developed to make nuclear fuels. ${ }^{24,25}$ Two types of laboratory-scale systems have been developed for sphere formation. The first type, shown in Figs. 1 and 2, makes use of a single-needle, two-fluid-nozzle system that is capable of producing 1 to $2 \mathrm{lb}$ of dried HTiO microspheres per day $(8 \mathrm{~h})$. The second system, which is used for making monodispersed microspheres with a vibrating-nozzle apparatus, is shown in Fig. 3. A tubular nozzle with two or three orifices would be needed for comparable production. Production could be increased by using a nozzle with five or seven orifices (Fig. 4). ${ }^{15}$

Prior to the start of this task in March 1996, microspheres of several materials had already been developed and prepared at ORNL by the HMTA internal gelation process. Hydrous titanium oxide and titanium monohydrogen phosphate microspheres and microspheres of both of these materials that were embedded, with very tine particles of potassium cobalt hexacyanoferrate were used successfully for removing highly radioactive fission products from hot cell waste solutions. ${ }^{26}$ The composite microspheres were very effective in removing cesium and strontium from supernatant taken from the Melton Valley Storage Tank (MVST) facility at ORNL. In a comparative study, they were found to be more effective than resorcinol/formaldehyde resin and CST for removing the cesium under certain conditions from the MVST supernatants and almost as effective as sodium 


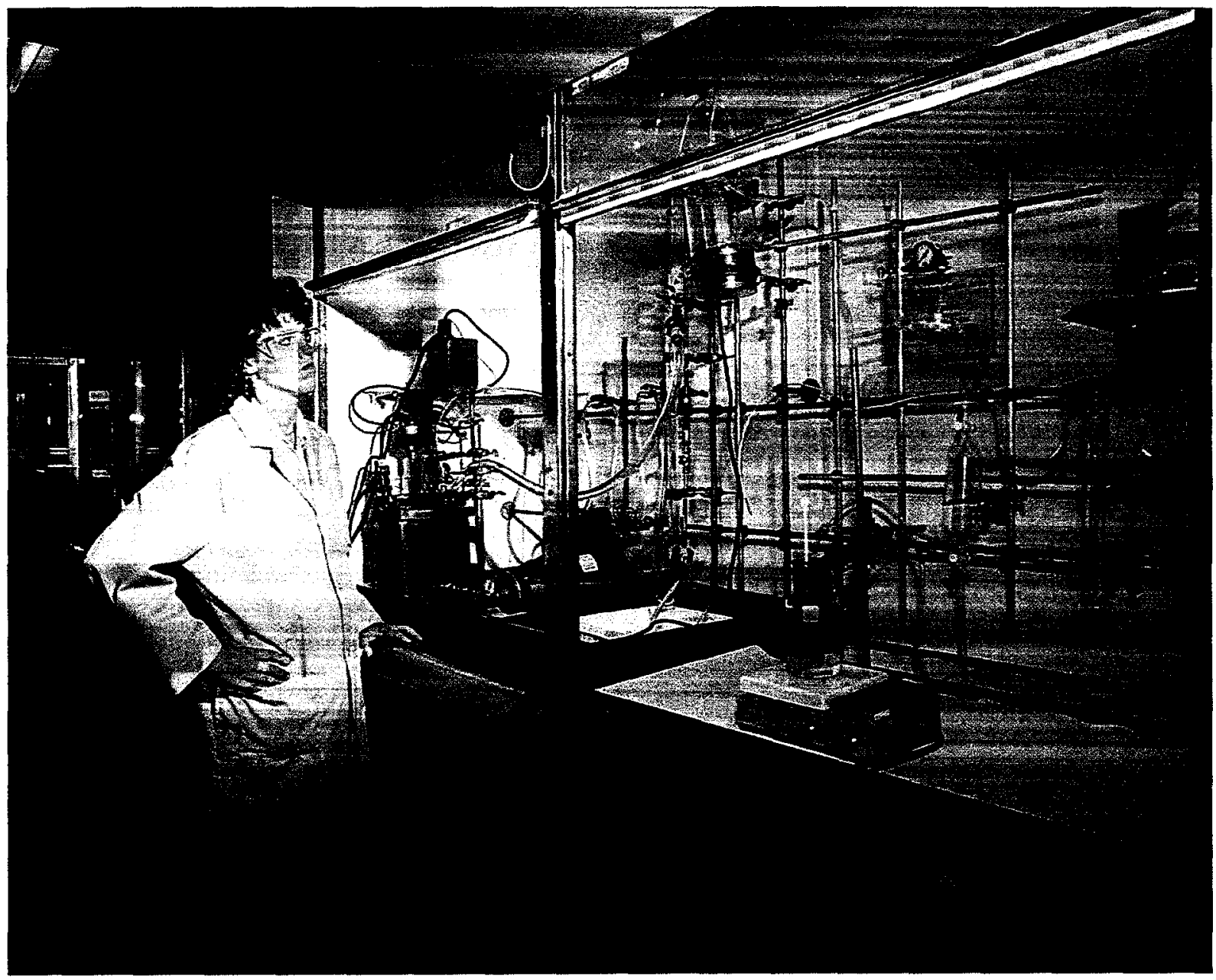

Fig. 1. Laboratory-scale system for forming monodispersed microspheres with a singleneedle, two-fluid nozzle.

titanate in removing the strontium." However, these composite microspheres can only be used to treat liquid waste streams with $\mathrm{pH} \leq 12$ because the potassium cobalt hexacyanoferrate (KCoCF) decomposes at higher $\mathrm{pH}$.

\section{CHEMICAL FLOW SHEET AND APPARATUS}

The broth formulations and process conditions used for making hydrous zirconium oxide by the HMTA internal gelation process were determined during previous work conducted at ORNL. ${ }^{28,29}$ Being able to make hydrous zirconium oxide $(\mathrm{HZrO})$ as microspheres is the key to making all of the sorbents in this program. 


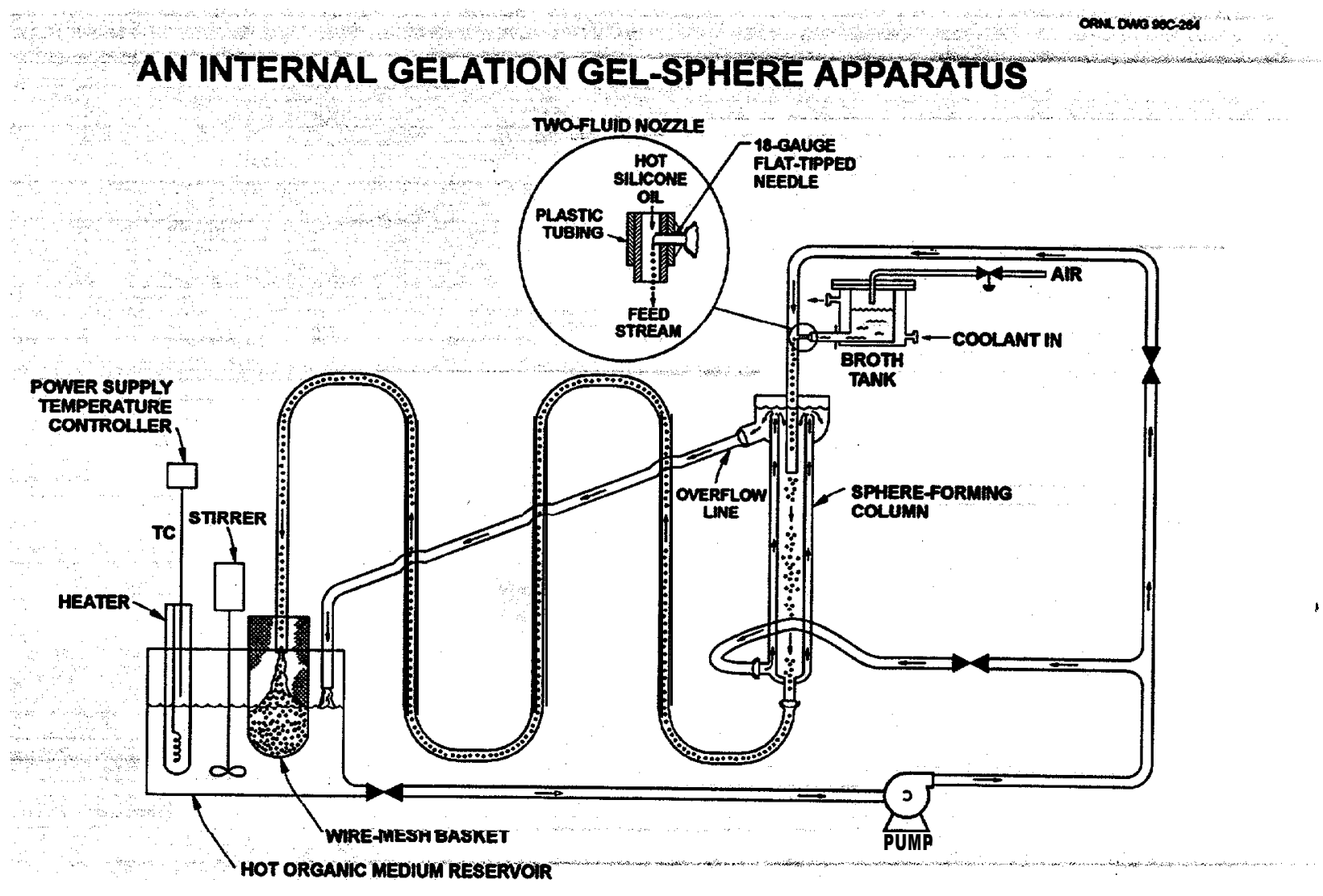

Fig. 2. Schematic of the laboratory-scale system for preparing microspheres with a singleneedle, two-fluid nozzle.

The basic chemical flow diagram is given in Fig. 5. The procedure for making $\mathrm{HZrO}$ microspheres by this process involves first mixing formulated amounts of HMTA, urea, and zirconyl nitrate (acidified with a predetermined amount of nitric acid) ${ }^{29}$ at temperatures near $0^{\circ} \mathrm{C}$ to form a broth. Broth formulations that remain clear and free of gel for reasonable periods of time ( $\geq 1 \mathrm{~h})$ are used. To make the HZrO/AMP microspheres, a predetermined amount of AMP is also mixed into the broth. The AMP is allowed to soak in a predetermined amount of water for about $24 \mathrm{~h}$ and is added as slurry to the broth tank. To keep particles of AMP suspended, the broth is continuously mixed in the chilled broth tank while the broth was pressure injected as droplets via a flat-tipped stainless steel hypodermic needle into a flowing stream of heated organic medium (Fig. 2). From there, the droplets are transported into the gel-forming apparatus. The size of the droplets is controlled by using a two-fluid nozzle concept and varying the gauge of the needle and the flow rates of the hot organic medium and the broth. Broth formulations with gel times of 8 to $12 \mathrm{~s}$ in the 


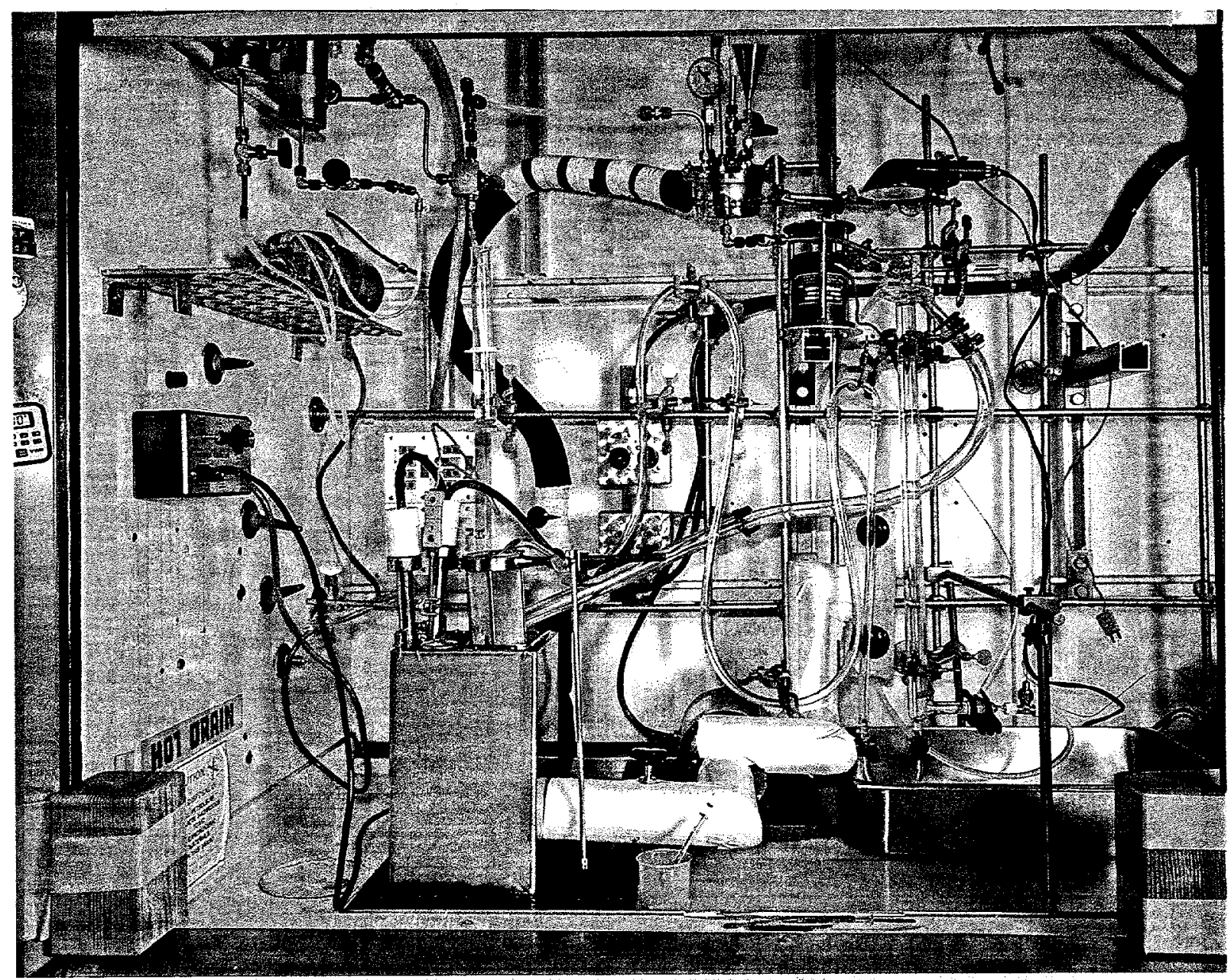

Fig. 3. Laboratory-scale system for forming monodispersed microspheres with a vibratingnozzle system.

organic medium temperature range of 70 to $90^{\circ} \mathrm{C}$ are used. It takes about $35 \mathrm{~s}$ for the gelling droplets to pass through the sphere-forming column and the serpentine residence tube to a collection basket (a cylindrical stainless steel-wire mesh basket). The basket with the collected microspheres is lowered into the reservoir of hot organic medium, and the microspheres are aged for 10 to $30 \mathrm{~min}$. The reaction impurities are removed from the microspheres by washing them several times with $0.1 \mathrm{~A} 4 \mathrm{NH}_{4} \mathrm{NO}_{3}$.

\section{CHEMISTRY OF THE HMTA INTERNAL GELATION PROCESS}

The chemistry of the HMTA internal gelation process is described in detail in reports by J. L. Collins et al. ${ }^{30,31}$ The results of those studies showed that there were four principal reactions 


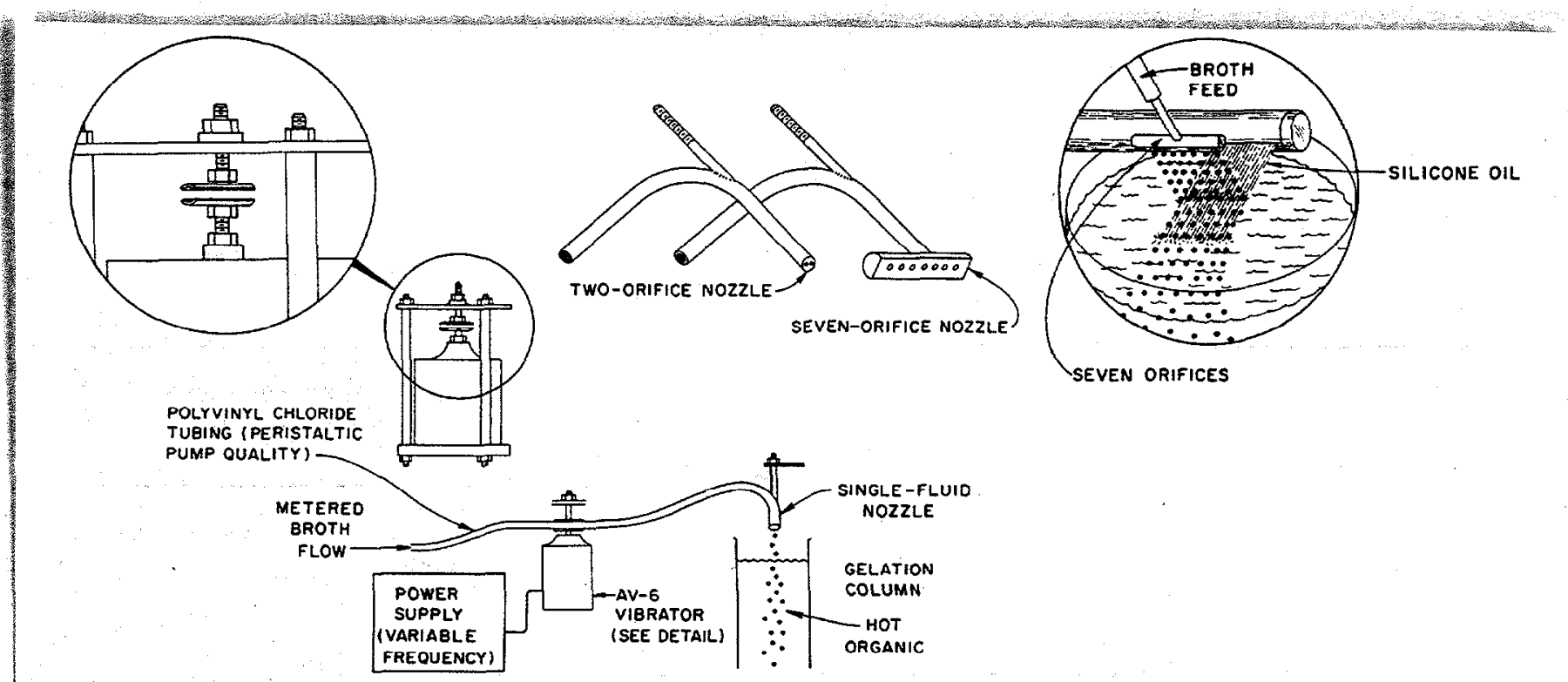

Fig. 4. Schematic of single-fluid pulsed tubular nozzles used to increase the production of microspheres.

involved in the hydrolysis and precipitation of uranyl nitrate hexahydrate and that the kinetics and equilibria of these reactions varied with temperature. The chemical behavior observed in these studies should hold true for making microspheres of other hydrous metal oxides by the HMTA internal gelation process. The four reactions for making $\mathrm{HZrO}$ can be shown as follows:

complexation/decomplexation

$$
2 \mathrm{CO}\left(\mathrm{NH}_{2}\right)_{2}+\mathrm{Zr}^{4+} \neq \mathrm{Zr}\left[\mathrm{CO}\left(\mathrm{NH}_{2}\right)_{2}\right]_{2}^{4+},
$$

\section{hydrolysis}

$$
\begin{aligned}
& \mathrm{Zr}^{4+}+x \mathrm{H}_{2} \mathrm{O} \rightleftharpoons \mathrm{Zr}(\mathrm{OH})_{4} \cdot y \mathrm{H}_{2} \mathrm{O} 1+4 \mathrm{H}^{+} \text {and } \\
& \mathrm{ZrO}^{2+}+x \mathrm{H}_{2} \mathrm{O} \rightleftharpoons \mathrm{ZrO}(\mathrm{OH})_{2} \cdot y \mathrm{H}_{2} \mathrm{O} \downarrow+2 \mathrm{H}^{+},
\end{aligned}
$$

\section{HMTA protonation}

$$
\left(\mathrm{CH}_{2}\right)_{6} \mathrm{~N}_{4}+\mathrm{H}^{+} \Rightarrow\left(\mathrm{CH}_{2}\right)_{6} \mathrm{~N}_{4} \cdot \mathrm{H}^{+} \text {, and }
$$




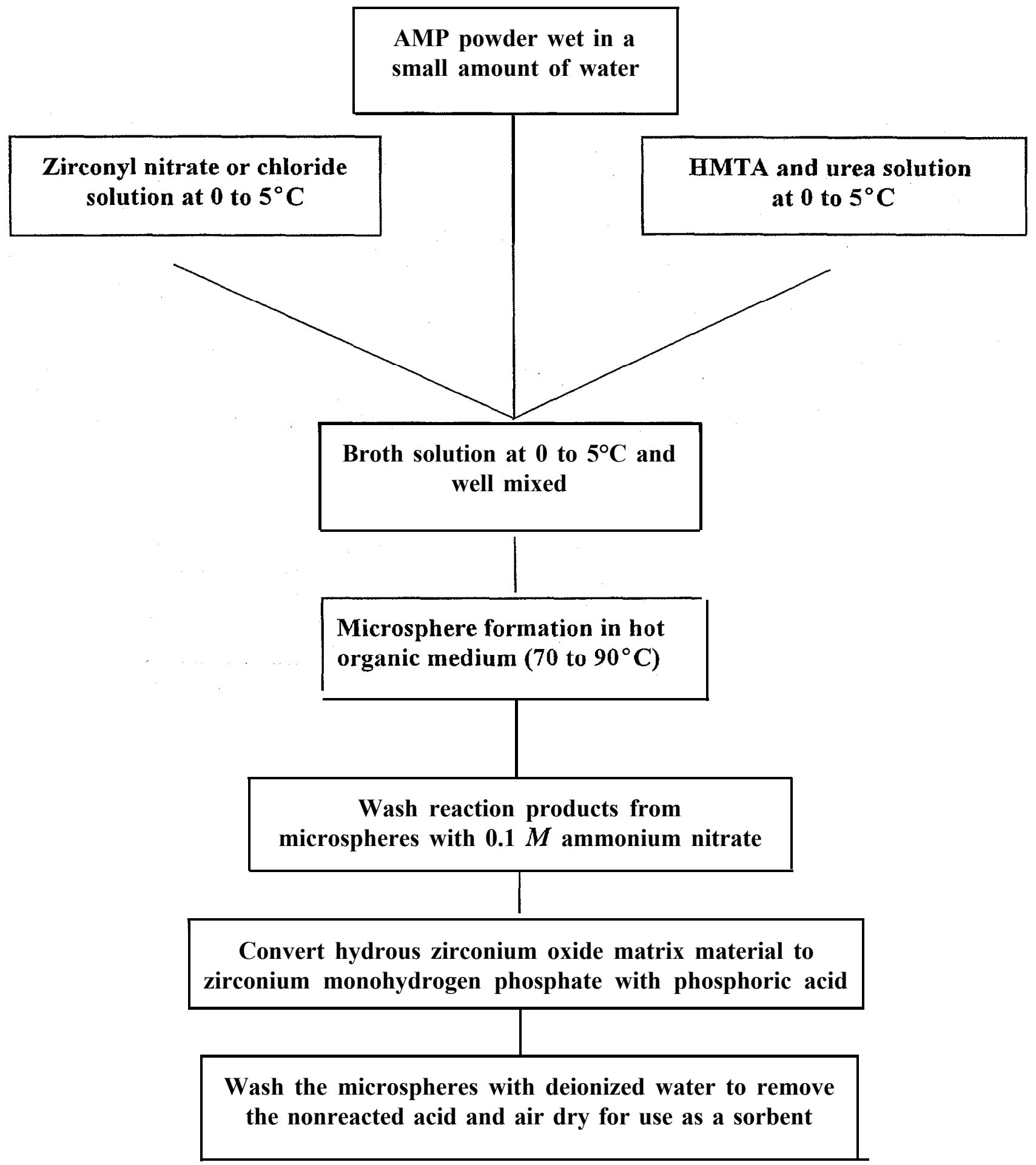

Fig. 5. Internal gelation flow sheet for making AMP-ZrHP microspheres. 


\section{HMTA decomposition}

$$
\left(\mathrm{CH}_{2}\right)_{6} \mathrm{~N}_{4} \cdot \mathrm{H}^{+}+3 \mathrm{H}^{+}+6 \mathrm{H}_{2} \mathrm{O} \rightleftharpoons 4 \mathrm{NH}_{4}^{+}+6 \mathrm{CH}_{2} \mathrm{O} \text {. }
$$

The major components of a broth used to make $\mathrm{HZrO}$ microspheres are HMTA, urea, and zirconyl nitrate. Urea serves as a complexing agent for the metal (reaction 1) and at certain concentrations allows for stable broths to be prepared at $0^{\circ} \mathrm{C}$ that remain clear and free of gelation or precipitation for reasonable periods of time. As the temperature of the broth droplets rises in the hot organic medium, decomplexation occurs (reaction 1), allowing hydrolysis of the zirconium to occur (reaction 2). HMTA, a weak organic base, drives the hydrolysis reaction to completion. At first the HMTA molecules are singularly protonated (reaction 3). Once most of the HMTA molecules ( $295 \%$ ) are protonated, they begin to decompose (reaction 4) into ammonia molecules, which make the system even more basic. Each protonated HMTA molecule can effectively remove three additional hydrogen ions, The reaction products are ammonium salt and formaldehyde $\left(\mathrm{CH}_{2} \mathrm{O}\right)$. In addition to being a complexing agent, urea also functions as a catalytic agent in the decomposition of protonated HMTA molecules. ${ }^{31}$

One of the more interesting features of the chemistry of this process is the conversion of the reaction products back to HMTA in the basic wash step. The gelled hydrous metal oxide microspheres are normally washed with 0.1 to $0.5 \mathrm{~A}_{4} \mathrm{NH}_{4} \mathrm{OH}$ to remove the reaction products ( $\mathrm{NH}$,' and $\mathrm{CH}_{2} \mathrm{O}$ ). The reaction products then react to reform HMTA, ${ }^{32}$ which is washed from the microspheres along with unreacted urea. This feature makes it possible, by chemical adjustments, to convert evaporator concentrates of the wash solutions back to process-usable HMTA/urea solutions. This feature aids in making the HMTA internal gelation process even more economically attractive. ${ }^{15}$ In the HZrO-AMP preparations the composite microspheres are washed with $0.1 \mathrm{MNH}_{4} \mathrm{NO}_{3}$. It is important to keep the $\mathrm{pH}$ of the wash solution $<7$ to prevent the dissolution of the AMP. To recycle the wash solution, enough $\mathrm{NH}_{4} \mathrm{OH}$ needs to be added to adjust the $\mathrm{pH}$ to about 7 to convert the reaction products back to HMTA. ${ }^{32}$

The lattices of the gels are thought to be formed by the chaining of colloidal particles of hydrolytic products of the zirconium. The most important factor in the formation of the gel spheres is the timing of the gelation of the aqueous broth droplets once they are introduced into the hot immiscible organic medium. Ideally, the droplets should be almost completely gelled after passing 
through the gel-forming apparatus to the collection basket. The broth formulations and gel-forming temperatures used to make the $\mathrm{HZrO}$ have been optimized to yield structurally strong microspherical sorbents. $^{29}$

\section{DEVELOPMENT OF ZRHP-AMP SPHEROIDAL SORBENT}

This task focused on the development of cesium-specific spherical sorbents for the treatment of acidic high-salt waste solutions. Zirconium monohydrogen phosphate (ZrHP) embedded with AMP as the cesium-selective inorganic sorbent was chosen for making microspheres. The internal gelation process for making $\mathrm{HZrO}$ microspheres provided a means in which very fine AMP particles were homogeneously dispersed throughout the matrix of the microspheres. Onceprepared, the composite gel spheres were treated with phosphoric acid, converting the $\mathrm{HZrO}$ to acid-insoluble $\mathrm{ZrHP}$ microspheres containing the AMP.

\subsection{AMMONIUM MOLYBDOPHOSPHATE}

Ammonium molybdophosphate (AMP) is a yellow powder with a microcrystalline structure that is a very effective sorbent for removing cesium from salt-bearing waste streams for a wide range of acidity.' AMP is effective in removing cesium over the full range of acidity but works best in a molarity range of 0.1 to 3 . The concentration of sodium was experimentally found to have little effect on the loading capacity of cesium. ${ }^{2}$ The cesium loading kinetics is even faster at $80^{\circ} \mathrm{C}$. At ambient temperature, the cesium loading capacity is $0.9 \pm 1 \mathrm{meq} / \mathrm{g}(120 \pm 13 \mathrm{mg} / \mathrm{g})$. This amount of aged fission-product cesium would contain about $40 \mathrm{mg}{ }^{137} \mathrm{Cs}$, which calculates to about $3.5 \mathrm{Ci}$ $(-16 \mathrm{R} / \mathrm{h}$ at a distance of $1 \mathrm{ft})$. If a kilogram of AMP were loaded with cesium $\left(-40 \mathrm{~g}{ }^{137} \mathrm{Cs} / \mathrm{kg}\right)$, about $18 \mathrm{~W}\left(0.45 \mathrm{~W} / \mathrm{g}{ }^{137} \mathrm{Cs}\right)$ would be generated. AMP selectivity for the following monovalent cations is as follows: $\mathrm{Cs}^{+}>\mathrm{Rb}^{+}>\mathrm{Tl}^{+}>>\mathrm{K}^{+}>\mathrm{Ag}^{+}>\mathrm{Hg}_{2}{ }^{2+}>>\mathrm{Na}^{+}$. In the $\mathrm{pH}$ range of 2-5, divalent (Sr and $\mathrm{Ba}$ ) and trivalent (Y, Ce, Sc) ions exchange are also significantly sorbed by AMP." Cesium can also be eluted from AMP with ammonium nitrate or chloride salt solutions (best at $-5 M$ ). In alkaline solutions ( $\mathrm{pH}>7$ ), AMP decomposes readily but reforms when the solution is acidified. 


\subsection{ZIRCONIUM MONOHYDROGEN PHOSPHATE}

Zirconium monohydrogen phosphate ( $\mathrm{ZrHP})$ does not sorb cesium in strongly acidic solutions; however, in the $\mathrm{pH}$ range of 2 to $10, \mathrm{ZrHP}$ is also a very effective sorbent for removing $\mathrm{Cs}, \mathrm{Sr}, \mathrm{Th}$, $\mathrm{U}(\mathrm{VI}), \mathrm{Pu}(\mathrm{IV}), \mathrm{Am}(\mathrm{III}), \mathrm{Hg}$, and $\mathrm{Pb}$ from streams of lower ionic concentrations. The best cesium loading capacity, $-0.8 \mathrm{meq} / \mathrm{g}(-100 \mathrm{~g} / \mathrm{kg})$, was achieved at a $\mathrm{pH}$ of $7 .^{2}$ However, there is a significant loss of cesium loading capacity in solutions with a high salt content. The composite microsphere developed in this task is a totally inorganic sorbent, is insoluble in acid medium, and has the advantage of being stable in high radiation fields. ZrHP-AMP microspheres loaded with cesium could be stored for indefinite periods or the cesium could be desorbed from the sorbent with ammonium salt solutions.

\subsection{DEVELOPMENT AND PREPARATION OF ZrHP-AMP COMPOSITE MICROSPHERES}

Three AMP powders were considered for the ZrHP-AMP microsphere development. One, AMP-I, was purchased from Bio-Rad Laboratories, Hurcules, California. The other two were prepared by Method A, a citromolybdate method described in a paper by J. L. Kassner, ${ }^{33}$ and Method B, a phosphomolybdic acid and ammonium nitrate method.* Method B was used by J. Dolezal ${ }^{13}$ and by F. Sebesta. ${ }^{5,14}$ Method B involved adding equal volumes of $0.1 \mathrm{M}$ phosphomolybdic acid and 0.5 A4 ammonium nitrate and mixing. The precipitated AMP was subsequently washed with deionized water and dried at $110^{\circ} \mathrm{C}$ for $3 \mathrm{~h}$,

Cesium removal batch tests were conducted with samples of each AMP powder. MVST W-27 supernatant that was acidified to a $\mathrm{pH}$ of 0.8 was used. To better determine the effectiveness of cesium loading, cold cesium was also added to adjust the cesium concentration from about $1 \mathrm{mg} / \mathrm{L}$ to $100 \mathrm{mg} / \mathrm{L}$. The initial cesium contained $-8.1 \mathrm{mCi} / \mathrm{L}$. Duplicate batch tests were conducted using a supernatant-to-AMP ratio of 200 and a mixing time of about $24 \mathrm{~h}$. The treated supernatant was separated from the sorbent by centrifugation followed by filtration with $0.2-\mu \mathrm{m}$ syringe filters. The' cesium distribution ratios $\left(\mathrm{D}_{\mathrm{Cs}}\right)$ and percentages of cesium removed (\%R) obtained were as follows: Bio-Rad samples $(16,800 \mathrm{~mL} / \mathrm{g}$ and $98.7 \%)$ Method A samples $(5,500 \mathrm{~mL} / \mathrm{g}$ and $96.2 \%)$, and 
Method B (2,900 mL/g and 93.3\%). Between 18.7 and $19.7 \mathrm{mg}$ of cesium was loaded per gram of AMP, which was about one-third of the cesium loading capacity as determined by Faubel and Ali. ${ }^{2}$

An internal gelation broth formulation was selected that provided a quick gelation start time of $10 \mathrm{~S}$ at $90^{\circ} \mathrm{C}$ in the immiscible organic. A short gelation time is needed to ensure that the AMP powder remained homogeneously suspended throughout the matrix. Flow conditions in the sphereforming apparatus were adjusted to obtain a broth droplet size that yielded air-dried microspheres in the 300- to $600-\mu \mathrm{m}$ range. To prepare a broth, $8 \mathrm{~mL}$ of $15.8 \mathrm{MHNO}_{3}$ was added to a glass flask containing $56.5 \mathrm{~mL}$ of zirconyl nitrate 'solution (1.013 M Zr or $92.4 \mathrm{~g} \mathrm{Zr} / \mathrm{L})$. This solution was subsequently added to a 40-mL chilled solution of 3.2 A4 HMTA and 3.2 Murea and mixed well. The mole ratios of HMTA and urea to $\mathrm{Zr}$ and to $\mathrm{H}^{+}$were 2.22 and 1.0 , respectively. This volume of broth typically yielded about $104.5 \mathrm{~mL}(-130 \mathrm{~g})$ of washed, wet $\mathrm{HZrO}$ microspheres (with no AMP added), which, when air dried at ambient temperature for about 4 days, yielded about $10.42 \mathrm{~g}$. Conversion of the same mass of the wet $\mathrm{HZrO}$ microspheres to the phosphate form ( $\mathrm{rHP})$ and air drying them for 4 'days yielded about 14.4 g. To prepare ZrHP-AMP microspheres, a predetermined mass of AMP would be added to $56.5 \mathrm{~mL}$ of zirconyl nitrate in a glass flask, which would mix for several hours or overnight at ambient temperature. Prior to making the microspheres, $8 \mathrm{~mL}$ of $15.8 \mathrm{MHNO}_{3}$ was added to the flask, which was placed in an ice bath to chill. Afterward, this solution was subsequently added to a 40-n-L chilled solution of 3.2 A4 HMTA and 3.2 Murea and mixed well. The chilled broth was then added to the chilled broth tank of the internal gelation process apparatus with continued stirring to keep the AMP powder in suspension (Sect. 4).

Twelve preparations of AMP-HZrO microspheres were made and converted to AMP-ZrHP with phosphoric acid. Five of these preparations were made with fine AMP powder prepared by the citromolybdate method, and the other seven were made with Bio-Rad AMP-1 powder. Cesium removal batch tests were conducted with samples of air-dried ZrHP-AMP microspheres. The dryweight percentages of AMP for these preparations were in the range of 30 to 60. MVST W-27 supernatant that was acidified with nitric acid to a concentration of $0.16 M(\mathrm{pH} \mathrm{0.8)} \mathrm{was} \mathrm{used.} \mathrm{The}$ major constituents of the acidified supernatant were $\mathrm{Na}^{+}(4.86 M), \mathrm{K}^{+}(0.26 M)$, and $\mathrm{NO}_{3}{ }^{-}(5.34 M)$. Cold cesium was also added to increase the cesium concentration from about $1 \mathrm{mg} / \mathrm{L}$ to $101 \mathrm{mg} / \mathrm{L}$. The concentration of ${ }^{137} \mathrm{Cs}$ was about $8.4 \mathrm{mCi} / \mathrm{L}$. For comparison, similar tests were also conducted with a composite sorbent AMP-PAN which was obtained from F. Sebesta at the Czech Technical University in Prague, Czech Republic, This sorbent is composed of AMP powder, which is bound 
in an organic polymer of PAN. Duplicate tests were conducted using a ratio of supernatant volume $(\mathrm{mL})$ to a mass of dry sorbent $(\mathrm{g})$ of 200 and a mixing time of $\mathbf{- 2 4} \mathbf{~ h}$. The weight ratio of wet microspheres to air-dried microspheres ranged from 4.6 to 5.6 and was 4.2 for the AMP-PAN. The AMP-PAN was only tested as received in the undried form. The average distribution ratio (D) for the PAN-AMP samples was $7500 \mathrm{~mL} / \mathrm{g}$. About $97.5 \%$ of the cesium was removed. The best $\mathrm{D}$ for the air-dried ZrHP-AMP microspheres was $-5890 \mathrm{~mL} / \mathrm{g}$, with $96.9 \%$ of the cesium being removed; however, there was little difference in D values for the different weight percentages of AMP powder in the ZrHP microspheres.

\section{CHARACTERIZATION OF SORBENT}

\subsection{TGA MEASUREMENTS}

Samples of air-dried ZrHP microspheres, PHOZIR A (a granular zirconium monohydrogen phosphate sorbent made by Recherche Applique du Nord, France), and samples of urea, HMTA, and $\mathrm{NH}_{4} \mathrm{NO}_{3}$ were analyzed by thermogravimetric (TGA) analysis in $100 \%$ nitrogen and in $100 \%$ oxygen. Each sample was heated at a rate of $1{ }^{\circ} \mathrm{C} / \mathrm{min}$ from 50 to $-500^{\circ} \mathrm{C}$ in a flowing dry-air atmosphere. PHOZIR A was analyzed to see how the ZrHP microspheres compared. Figures 6 and 7 give the results in percentage weight loss as a function of temperature. For ZrHP and PHOZIR A, the weight loss profiles were almost identical, showing that the reaction additives and products in $\mathrm{ZrHP}$ microspheres were removed in the washing step. If there had been significant HMTA, urea, and $\mathrm{NH}_{4} \mathrm{NO}_{3}$ present in the matrix of the ZrHP microspheres, there would have been noticeable changes in the ZrHP microspheres weight loss profile at the upswing locations indicated by the FMTA, urea, and $\mathrm{NH}_{4} \mathrm{NO}_{3}$ profiles. This was not the case. The initial sample weights ranged from 0.14 to $0.22 \mathrm{~g}$. A weight loss in ZrHP microspheres and the PHOZIR A of $-10 \%$ was observed in the temperature range of 50 to $150^{\circ} \mathrm{C}$ in which most of the occluded water and water of hydration would be expected to vaporize. A rapid weight loss from the HMTA and urea samples was also experienced at temperatures above $160^{\circ} \mathrm{C}$ and above $200^{\circ} \mathrm{C}$ for the $\mathrm{NH}_{4} \mathrm{NO}_{3}$. 


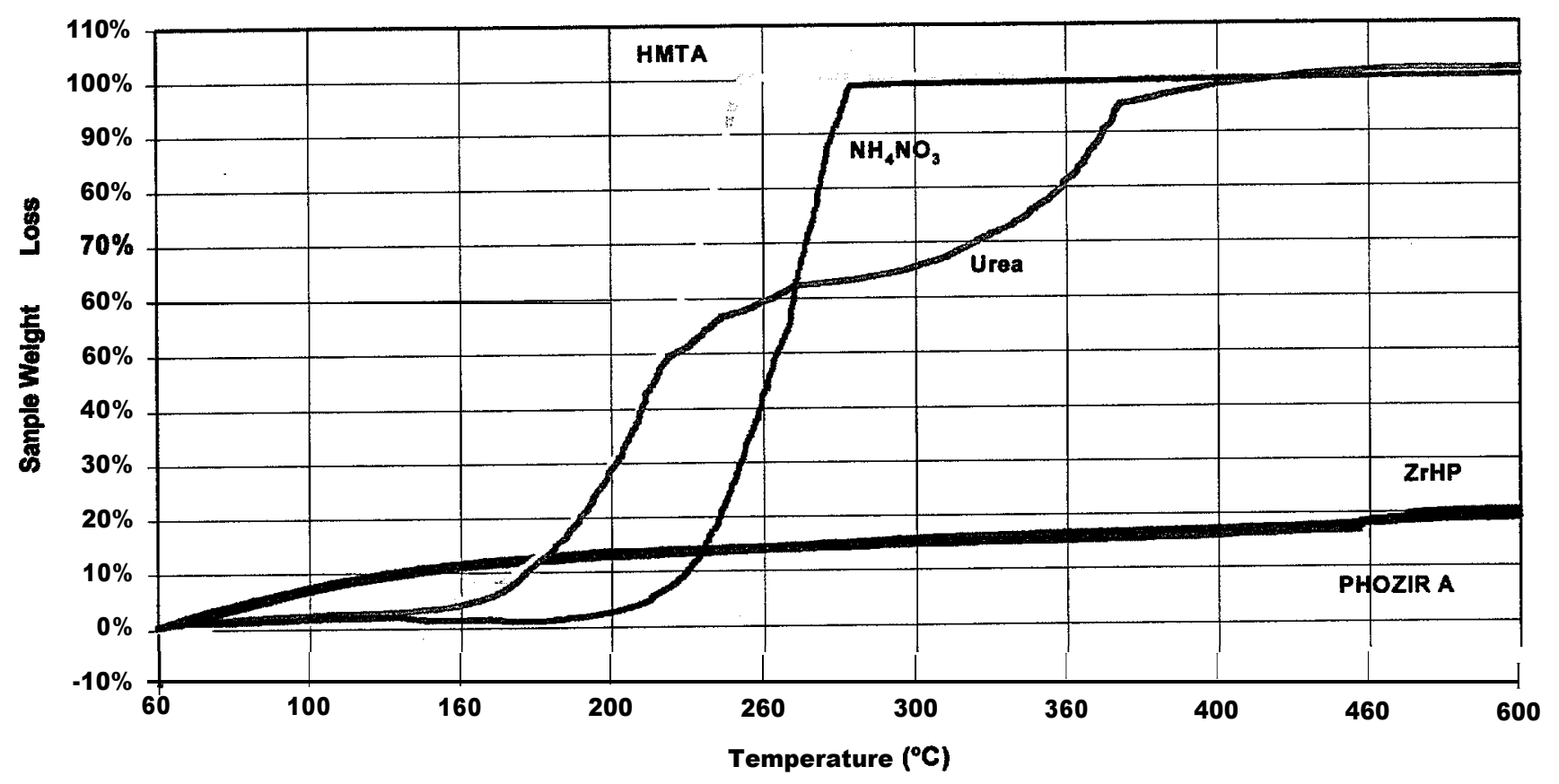

Fig. 6. Weight loss from samples of ZrHP microspheres, PHOZIR A, and components of the internal gelation process by TGA in $100 \%$ nitrogen.

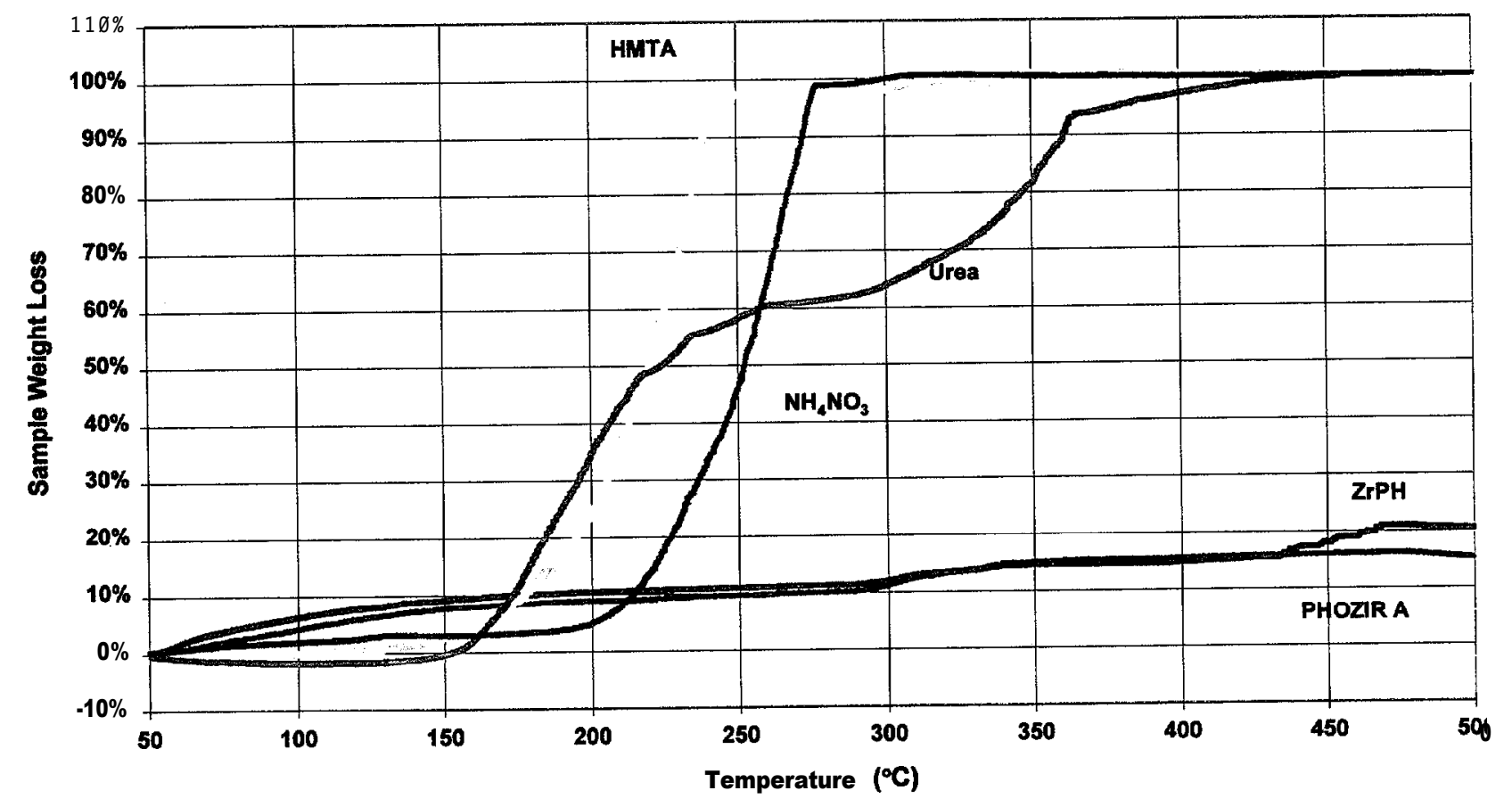

Fig. 7. Weight loss from samples of $\mathrm{ZrHP}$ microspheres, PHOZIR A, and components of the internal gelation process by TGA in $100 \%$ oxygen. 


\subsection{CRUSH STRENGTH MEASUREMENTS}

The average crush strength for each composite microsphere composition was determined dynamometrically. This is the force, in grams, needed to crush a single microsphere. For these measurements, twenty or more air-dried microspheres were randomly chosen from each composition and crushed (Table 1). The crush strength for ZrHP microspheres was $870 \pm 150 \mathrm{~g}$. As the weight percentage of the AMP was increased in the AMP/ZrHP microspheres from 30 to $60 \%$, the crust strength of the microspheres decreased. The values were: $550 \pm 141 \mathrm{~g}$ for $30 \mathrm{wt} \%$ AMP, $166 \pm$ $50 \mathrm{~g}$ for $40 \mathrm{wt} \%$ AMP, $50 \pm 25 \mathrm{~g}$ for $50 \mathrm{wt} \%$, and $8 \pm 3 \mathrm{~g}$ for $60 \mathrm{wt} \%$ microspheres. The goal was to embed as much AMP fine powder into the ZrHP microsphere as possible and maintain structural strength. The $50 \mathrm{wt} \%$ AMP was the maximum amount that can be used that provided adequate crush strength that would be needed for column use. This composite microsphere preparation was selected as the material to be sent to TNEEL.

Table 1. Dynamometric measurement of microspheres (crush strength in grams)

\begin{tabular}{lc}
\hline \multicolumn{1}{c}{ Microsphere" } & $\begin{array}{c}\text { Air dried } \\
(\mathrm{g})\end{array}$ \\
\hline $\mathrm{HTiO}$ & $>2000$ \\
23 wt \% NaTiO/HTiO & $>2000$ \\
18 wt $\% \mathrm{NaCoCF} / \mathrm{TiHP}$ & $662 \pm 154$ \\
$\mathrm{HZrO}$ & $>2000$ \\
ZrHP & $870 \pm 150$ \\
30 wt \% AMP/ZrHP & $550 \pm 141$ \\
40 wt \% AMP/ZrHP & $166 \pm 50$ \\
50 wt \% AMP/ZrHP & $50 \pm 25$ \\
60 wt \% AMP/ZrHP & $8 \pm 3$ \\
\hline
\end{tabular}

"Size of microspheres was in the range 350 to $<590 \mu \mathrm{m}$. 
The crush strengths of the pure $\mathrm{HZrO}$ and $\mathrm{HTiO}$ microspheres were also measured for comparison. Both had crush strengths of $>2000 \mathrm{~g}$. The addition of NaCoCF or KCoCF powders (up. to $25 \mathrm{wt} \%$ ) had little impact on the crush strength; both remained at $>2000 \mathrm{~g}$. This was also the case when sodium titanate $(\mathrm{NaTiO})$ was added to hydrous metal oxide microspheres. Conversion of the hydrous metal oxides to monohydrogen phosphates with phosphoric acid lessened the crush strength by a factor of two or more. Depending on the preparation method used, amorphous, semicrystalline, and crystalline microspheres can be prepared. As the crystallinity of the monohydrogen phosphate is increased, the structural strength of the microspheres is decreased. The composite TiHP or ZrHP microspheres prepared in this work were made amorphous to help maximize the structural strength.

\section{8. ВАTCH TESTS}

\subsection{PROCEDURE}

Sorption measurements were made using batch equilibration tests. The supernatant and the exchangers were contacted in 15-mL screw-cap polypropylene centrifuge tubes by mixing with a Labquake ${ }^{\mathrm{TM}}$ shaker. The mixer is set to rock from $-45^{\prime}$ to $+45^{\circ}$ from the horizontal plane in a backand-forth rocking motion at a rate of -20 cycles per minute. The exchangers and the supernatant were weighed in consecutive steps into tared tubes, The volumes of supernatant (normally about $5 \mathrm{~mL}$ ) were calculated from the specific gravity of the supernatant. At the end of the equilibration periods, the tubes were reweighed to determine if leakage had occurred. Afterward, $\sim 2-\mathrm{mL}$ volumes of the supernatants were transferred to clean centrifuge tubes by pipet and centrifuged for $10 \mathrm{~min}$ at $3000 \mathrm{rpm}$ with an International Equipment Company Centra 7 tabletop centrifuge. With a syringe filtering system, the clarified supernatants were filtered successively through $0.2-\mu \mathrm{m}$ nylon filters to remove any of the remaining fine particulates. Samples $(0.5 \mathrm{~mL})$ of the filtered supernatant were pipetted into counting tubes for radiochemical analysis. The ${ }^{137} \mathrm{Cs}$ activity was determined using a LKB Wallac 1282 Compugamma Universal Gamma Counter. 
Sorption data for equilibration times of 1 and $24 \mathrm{~h}$ at ambient temperature were determined for each exchanger tested. Most tests used about $0.025 \mathrm{~g}$ of exchanger and a supernate volume of about $5 \mathrm{~mL}$, giving a solution-to-solid ratio of $200 / 1$.

\subsection{CALCULATIONS}

Batch test results are reported as percentage removal $(\% R)$ and distribution ratio $(D,$,$) . These$ values are calculated in the following manner:

$$
\% R=100\left(\frac{C_{o}-C_{t}}{C_{o}}\right)
$$

$\mathrm{C}_{\mathrm{o}}=$ Initial counts per minute of sample (counts per minute before contact).

$\mathbf{C}_{\mathbf{t}}=$ Final counts per minute of sample at time $\mathrm{t}$ (counts per minute of sample after contact time $\mathrm{t}$ ).

$$
D_{C s}=\left(\frac{C_{0}-C_{t}}{C_{t}}\right) \times\left(\frac{V}{m}\right)(\text { measured as } \mathrm{mL} / \mathrm{g} \text { ) }
$$

$\mathrm{V}=$ Volume of supernatant added.

$\mathrm{m}=$ Mass of sorbent added.

The $\mathrm{D}_{\mathrm{Cs}}$ compares the mass of the radionuclide on the ion exchanger with the mass remaining in solution after the specified contact time $(\mathrm{t})$.

\subsection{COMPARATIVE CESIUM REMOVAL BATCH TEST RESULTS}

ZrHP-AMP microspheres which contained 50\% AMP (based on the dry weight) were chosen to be used for shipment to INEEL for small-column testing with real NNEEL acidic sodium-bearing 
liquid waste. Using crush strength measurements (Sect, 7.2), it was determined that'higher weight percentages of AMP decreased the structural strength of the microspheres too severely for column use.

Cesium removal batch tests were conducted with two stock solutions of MVST W-27 supernatant that were acidified with concentrated nitric acid to a free acid concentration of 0.16 $(\mathrm{pH}=0.8)$ and 1.8 molar acid. The concentrations of the constituents of MVST W-27 supernatant and of the two acid-adjusted stock solutions are given in Table 2. For comparison purposes, the concentrations of the constituents in NNEEL WM-183 are also given. To better determine the effectiveness of cesium loading for the microspheres, cold cesium was also added to the two stock solutions to adjust the cesium concentration from about $1 \mathrm{mg} / \mathrm{L}$ to $101 \mathrm{mg} / \mathrm{L}$, which is ten times more cesium than was present in the INEEL WM- 183 supernatant. Furthermore, the concentrations of the sodium and potassium in the two stock solutions were $\sim 6.6$ and 2.7 times greater. On the other hand, the concentrations of aluminum, calcium, chromium, lead, and uranium were much higher in the INEEL WM-183 supernatant. The two stock solutions contained about $8.4 \mathrm{mCi} / \mathrm{L}$ of ${ }^{137} \mathrm{Cs}$, which was more than enough gamma activity to provide good counting accuracy.

For comparison, similar batch tests were also conducted with samples of KCoCF (18 wt \%)TiHP microspheres, NaCoCF (18 wt \%)-TiHP microspheres, granular KCoCF, pure ZrHP microspheres, AMP-1 powder, and AMP (85 wt \%)-PAN. Microspheres containing the AMP worked well in removing the cesium from the MVST W-27 supernatant that was acidified to $0.16 M$ free acid (Table 3$)$. The $\mathrm{D}_{\mathrm{Cs}}$ and $\% \mathrm{R}$ for $1-$ and $24-\mathrm{h}$ mixing times were $532 \mathrm{~mL} / \mathrm{g}(72 \%)$ and $5890 \mathrm{~mL} / \mathrm{g}(96.9 \%)$ respectively. The AMP (85 wt \%)-PAN was slightly more effective, providing $\mathrm{D}_{\mathrm{Cs}}$ and $\% \mathrm{R}$ of $966 \mathrm{~mL} / \mathrm{g}(82.9 \%)$ and $7500 \mathrm{~mL} / \mathrm{g}(97.5 \%)$ for $1-$ and $24-\mathrm{h}$ mixing times, respectively. However, the AMP (85 wt \%)-PAN contained 1.7 times more AMP than the AMP (50 wt \%)-ZrHP microspheres. The calculated mass of cesium loaded on $1 \mathrm{~g}$ of the AMP powder in the microspheres was $38.8 \mathrm{mg}$ in the 24-h tests compared with $22.9 \mathrm{mg}$ for $1 \mathrm{~g}$ of the AMP in the PAN sorbent. In the $24-\mathrm{h}$ batch tests, pure AMP-1 powder provided a $\mathrm{D}_{\mathrm{Cs}}$ of $16,800 \mathrm{~mL} / \mathrm{g}$, removing 98.7\% of the cesium. As expected, the ZrHP microspheres did not remove any cesium.

The data in Table 3 also shows that granular KCoCF (obtained from Eichrom Industries, Inc.) worked almost as well as the powdered AMP-1. Both the KCoCF (18 wt \%)-TiHP and NaCoCF (18 wt \%)-TiHP microspheres were effective in removing cesium but did not perform as well as the 
Table 2. Analytical data for MVST W-27 supernatant and acidified MVST W-27 supernatant

\begin{tabular}{|c|c|c|c|c|}
\hline & $\begin{array}{c}\mathrm{w}-27 \\
(\mathrm{pH}=12.8)\end{array}$ & $\begin{array}{c}\mathrm{W}-27 ” \\
\left(0.16 M \mathrm{MH}^{+}\right)\end{array}$ & $\begin{array}{c}W-27^{a} \\
\left(1.8 M \mathrm{H}^{+}\right)\end{array}$ & $\begin{array}{l}\text { INEEL WM-183 } \\
\quad\left(1.77 M \mathrm{H}^{+}\right)\end{array}$ \\
\hline Radionulitides. & $(B d /)^{3}$ & $(\mathrm{~Bq} / \mathrm{L})$ & $(\mathrm{Bq})$ & (Bq/1) \\
\hline $137 \mathrm{Cs}$ & $32 \mathrm{E}+08$ & $3 / \mathrm{E}+08$ & $2.8 \mathrm{E}+08$ & $817+09$ \\
\hline${ }^{6} c_{0}$ & $6.8 \mathrm{E}+05$ & $6.5 \mathrm{E}+05$ & $600 \mathrm{~B}+05$ & ND \\
\hline $169 \mathrm{~S}_{\mathrm{I}}$ & $65 \mathrm{E}+0 \%$ & $62 \mathrm{E}+06$ & $571+06$ & $74 \mathrm{E}+09$ \\
\hline Other metals & $(\mathrm{mg} / \mathrm{L})$ & $(\mathrm{mg} / \mathrm{L})$ & $(\mathrm{mg} / \mathrm{L})$ & (mg/L) \\
\hline $\mathrm{Al}$ & 0.85 & 0.81 & 0.75 & 17,260 \\
\hline $\mathrm{Ba}$ & 8.04 & 7.65 & 7.02 & ND \\
\hline $\mathrm{Ca}$ & 89.1 & 84.8 & 78.6 & 1,600 \\
\hline CS & 0.94 & 100.9 & 100.8 & 9.5 \\
\hline $\mathrm{Cr}$ & 3.0 & 2.8 & 2.6 & 728 \\
\hline $\mathrm{K}$ & 10,800 & 10,280 & 9,530 & 3,680 \\
\hline $\mathrm{Na}$ & 113,000 & 107,560 & 99,700 & 15,640 \\
\hline $\mathrm{Pb}$ & 0.01 & 0.01 & 0.01 & 250 \\
\hline $\mathrm{Sr}$ & ND” & ND & ND & ND \\
\hline $\mathrm{U}$ & $<1.0$ & $<1.0$ & $<1.0$ & 114 \\
\hline Anions & $(\mathrm{mg} / \mathrm{L})$ & $(\mathrm{mg} / \mathrm{L})$ & $(\mathrm{mg} / \mathrm{L})$ & $(\mathrm{mg} / \mathrm{L})$ \\
\hline $\mathrm{Br}^{-}$ & 288 & 274 & 254 & ND \\
\hline $\mathrm{Cl}^{-}$ & 3,180 & 3,030 & 2,810 & 390 \\
\hline $\mathrm{F}^{-}$ & $<8$ & $<8$ & $<8$ & ND \\
\hline $\mathrm{NO},-$ & 322,000 & 353,900 & 400,700 & 324,900 \\
\hline $\mathrm{PO}_{4}^{3-}$ & $<30$ & $<30$ & $<30$ & ND \\
\hline $\mathrm{SO}_{4}{ }^{2-}$ & 1,540 & 1,470 & 1,360 & 6,340 \\
\hline
\end{tabular}

"Calculated values based on addition of $15.8 \mathrm{MHNO}_{3}$ to samples of W-27 supematant.

${ }^{b} 1 \mu \mathrm{Ci}=37,000 \mathrm{~Bq}$.

ND = not determined. 
Table 3. Removal of cesium from acidified MVST W-27 supernatant $\left(0.16 M \mathrm{H}^{+}\right)$

\begin{tabular}{|c|c|c|c|c|}
\hline \multirow[b]{3}{*}{ Sorbent" } & \multicolumn{4}{|c|}{ Mixing time } \\
\hline & \multicolumn{2}{|c|}{$1 \mathrm{~h}$} & \multicolumn{2}{|c|}{$24 \mathrm{~h}$} \\
\hline & $\begin{array}{c}D^{b} \\
(\mathrm{~mL} / \mathrm{g})\end{array}$ & $\% \mathrm{R}$ & $\begin{array}{c}\mathrm{D}^{b} \\
(\mathrm{~mL} / \mathrm{g})\end{array}$ & $\% \mathrm{R}$ \\
\hline $\mathrm{KCoCF}(18 \mathrm{wt} \%)-\mathrm{TiHP} \theta^{\circ}$ & 300 & 58.0 & 998 & 83.1 \\
\hline $\mathrm{KCoCF}(\mathrm{gr}) "$ & 880 & 81.8 & 10240 & 98.1 \\
\hline $\mathrm{NaCoCF}\left(18\right.$ wt \%)-TiHP $\theta^{c}$ & 123 & 37.1 & 1200 & 85.3 \\
\hline IONSIV ${ }^{\circledR}$ IE-9 11 (gr)" & & & 670 & 77.0 \\
\hline AMP- 1 (powder) & & & 16800 & 98.7 \\
\hline $\mathrm{ZrHP} \Theta^{c}$ & 0 & 0 & 0 & 0 \\
\hline $\operatorname{AMP}(50$ wt $\%)-\mathrm{ZrHP} \theta^{c}$ & 532 & 72.0 & 5890 & 96.9 \\
\hline $\operatorname{AMP}(85$ wt \%)- PAN," Czech & 966 & 82.9 & 7500 & 97.5 \\
\hline $\begin{array}{l}{ }^{a} \Theta=\text { microspheres }(350 \text { to }<59 \\
{ }^{b} \text { Supernatant/sorbent ratio }=-2 \\
\text { 'Microspheres were air dried. } \\
{ }^{d} \text { gr }=\text { granular }(350 \text { to }<590 \mu \mathrm{r} \\
\text { "Microspheres were not dried. }\end{array}$ & im) & & & \\
\hline
\end{tabular}

AMP (50 wt \%)-ZrHP microspheres; however, the AMP-ZrHP microspheres contained much more active sorbent. IONSIV ${ }^{\circledR}$ IE-911 also was found effective in removing cesium from this supernatant. The $24-\mathrm{h} \mathrm{D}_{\mathrm{Cs}}$ and \% R were $670 \mathrm{~mL} / \mathrm{g}$ and $77 \%$, respectively.

Table 4 gives the cesium removal results for the MVST W-27 supernatant that was acidified to 1.8 A4 free acid. The increased acid concentration had an impact on all the sorbents, lowering the $\mathrm{D}_{\mathrm{Cs}}$ and \% R. For the 24-h tests, the granular KCoCF and the KCoCF (18 wt \%)-TiHP microspheres surprisingly worked best. The $\mathrm{D}_{\mathrm{Cs}}$ and $\% \mathrm{R}$ were $2800 \mathrm{~mL} / \mathrm{g}(93.2 \%)$ and $1650 \mathrm{~mL} / \mathrm{g}(88.8 \%)$ respectively. The $\mathrm{D}_{\mathrm{Cs}}$ and \% $\mathrm{R}$ values were also high for the $1 \mathrm{~h}$ tests, $1110 \mathrm{~mL} / \mathrm{g}(83.9 \%)$ and $1400 \mathrm{~mL} / \mathrm{g}(87.1 \%)$. The values for the AMP-1 powder, for the 24-h batch tests, were $1380 \mathrm{mg} / \mathrm{L}$ and $86.8 \%$ cesium removal. The AMP (85 wt \%)-PAN and air-dried AMP (50 wt \%)-ZrHP also were effective in removing the cesium. The $\mathrm{D}_{\mathrm{Cs}}$ and $\% \mathrm{R}$ for 1 - and $24-\mathrm{h}$ mixing times were $850 \mathrm{~mL} / \mathrm{g}(81.9 \%)$ and $1080 \mathrm{~mL} / \mathrm{g}(84.4 \%)$ for AMP (85 wt \%)-PAN and $306 \mathrm{~mL} / \mathrm{g}(61.4 \%)$ and 
Table 4. Removal of cesium from acidified MVST W-27 supernatant $\left(1.8 M \mathrm{H}^{+}\right)$

\begin{tabular}{|c|c|c|c|c|}
\hline \multirow[b]{3}{*}{ Sorbent" } & \multicolumn{4}{|c|}{ Mixing time } \\
\hline & \multicolumn{2}{|c|}{$1 \mathrm{~h}$} & \multicolumn{2}{|c|}{$24 \mathrm{~h}$} \\
\hline & $\begin{array}{c}\mathrm{D}^{b} \\
(\mathrm{~mL} / \mathrm{g})\end{array}$ & $\% \mathrm{R}$ & $\begin{array}{c}\mathrm{D}^{b} \\
(\mathrm{~mL} / \mathrm{g})\end{array}$ & $\% \mathrm{R}$ \\
\hline $\mathrm{KCoCF}(18$ wt $\%)-\mathrm{TiHP} \theta$ & 1400 & 87.1 & 1650 & 88.8 \\
\hline $\mathrm{KCoCF}$ (gr)" & 1110 & 83.9 & 2800 & 93.2 \\
\hline $\mathrm{NaCoCF}(18$ wt $\%)-\mathrm{TiHP} \theta$ & 174 & 46.3 & 730 & 78.1 \\
\hline IONSIV $^{\circledR} \mathrm{IE}-911(\mathrm{gr})^{d}$ & & & 349 & 62.5 \\
\hline AMP- 1 (powder) & & & 1380 & 86.8 \\
\hline $\mathrm{ZrHP} \theta^{c}$ & 0 & 0 & 0 & 0 \\
\hline $\operatorname{AMP}(50$ wt $\%)-\mathrm{ZrHP} \theta$ & 306 & 61.4 & 980 & 82.5 \\
\hline $\operatorname{AMP}(85$ wt \%)- PAN," Czech & 850 & 81.9 & 1080 & 84.4 \\
\hline $\begin{array}{l}{ }^{a} \theta=\text { microspheres }(350 \text { to }<59 \\
{ }^{b} \text { Supernatant/sorbent ratio }=- \\
\text { "Microspheres were air dried. } \\
{ }^{d} \text { gr }=\text { granular }(350 \text { to }<590 \mu \mathrm{r} \\
\text { "Microspheres were not dried. }\end{array}$ & (m) & & & \\
\hline
\end{tabular}

$980 \mathrm{~mL} / \mathrm{g}(82.5 \%)$ for the AMP (50 wt \%)-ZrHP. For IONSIV ${ }^{\circledR} \mathrm{IE}-911$, the $\mathrm{D}_{\mathrm{Cs}}$ and \% R for the 24-h mixing times was $349 \mathrm{~mL} / \mathrm{g}$ with $62.5 \%$ of the cesium removed. The pure $\mathrm{ZrHP}$ microspheres did not remove any cesium.

\section{SUMMARY}

A spheroidal composite inorganic sorbent was developed for potential use in cesium removal from acidic high-salt waste streams such as those at INEEL. The sorbent, ZrHP embedded with fine powder of AMP, was prepared using a unique internal gelation process which can be used to make porous reproducible microspheres that are structurally strong, have a low tendency for surface erosion, and improve the flow dynamics for column operations. The key to the development was to determine the ideal weight percentage of AMP that could be embedded in the ZrHP microspheres and 
maintain structural integrity and good cesium separation. To provide the highest loading with adequate structural strength, a composite microsphere that contained 50\% AMP (by dry weight measurement) was chosen. Another composite microsphere, KCoCF (18 wt \%)-TiHP, also prepared by the internal gelation process, was batch tested for comparison purpose and proved to be as effective in removing the cesium as the air-dried AMP (50 wt \%)-ZrHP AMP (85 wt \%)-PAN. Granular KCoCF was also very effective. Large samples of each of these materials were sent to INEEL for small-column testing with real waste.

\section{ACKNOWLEDGMENTS}

This research was sponsored by the Efficient Separations and Processing Crosscutting Program, Office of Environmental Management, U.S. Department of Energy. The authors wish to thank Debbie Stevens for editing this manuscript and Pam Tarlton for the preparation of the final manuscript.

\section{REFERENCES}

1. National Academy of Sciences, Alternative High-Level Waste Treatments at the Idaho National Engineering and Environmental Laboratory, National Academy Press, Washington, D.C., 1999.

2. W. Faubel and S. P. Ah, "Separation of Cesium from Acid ILW-Purex Solutions by Sorption on Inorganic Ion Exchangers," Radiochim. Acta 40, 49-56 (1986).

3. J. Lehto and R. Harjula, "Separation of Cesium from Nuclear Waste Solution with Hexacyanoferrate(II)s and Ammonium Phosphomolybdate," Solvent Ext. Ion Exch. 5(2), 343-352 (1987).

4. P. A. Haas, "A Review of Information on Ferrocyanide Solids for Removal of Cesium from Solutions," Sep. Sci. Technol. 28, 1479-1506 (1993).

5. F. Sebesta and J. John, An Overview of the Development, Testing, and Application of Composite Absorbers, LA-12875-MS (UC-721), February 1995. 
6. K. N. Brewer, T. A. Todd, A. L. Olson, D. J. Wood, V. M. Gelis, E. A. Kozlitin, and V. V. Milyutin, Cesium Removal from ICPP Acidic Waste with Potassium Copper Hexacyanoferrate, Report INEEL-96/0356, Idaho Falls, Idaho, 1996.

7. K. N. Brewer, T. A. Todd, and P. A. Tullock, The Use of a Russian Manufactured Potassium Copper Hexacyanoferrate to Remove Cesium from INTEC Radioactive Wastes, INEEL/EXT99/00663, Idaho Falls, Idaho, 1996.

8. J. van R. Smit, J. J. Jacobs, and W. Robb, "Cation Exchange on Ammonium Molybdophosphate-I The Alkali Metals," J. Inorg. Nucl. Chem. 12, 95-103 (1959).

9. J. van R. Smit and J. J. Jacobs, "Cation Exchange on Ammonium Molybdophosphate-I The Alkali Metals," J. Inorg. Nucl. Chem. 12, 104-1 12 (1959).

10. J. Krtil, "Exchange Properties of Ammonium Salts of 12-Heteropolyacids-IV Cs Exchange on Ammonium Phosphotungstate and Phosphomolybdate," J. Inorg. Nucl. Chenz. 24, 1139-1144 (1962).

11. J. van R. Smit and W. Robb, "Ion Exchange on Ammonium Molybdophosphate-II Bivalent and Trivalent Ions," J.Inorg. Nucl. Chem. 26, 509-518 (1964).

12. J. van R. Smit, "Ion Exchange on Ammonium Molybdophosphate-III Preparation and Properties of Coarse Ammonium Heteropolyacid Salts," J. Inorg. Nucl. Chem. 27, 227-232 (1965).

13. J. Dolezal, J. Stejskal, M. Tympl, and V. Kourim, "Improved Inorganic Ion-Exchangers- II. Ammonium Molybdophosphate — Silica Gel System," J. Radioanal. Chem. 21, 3 8 1-3 87 (1974).

14. F. Sebesta and V. Stefula, "Composite Ion Exchange with Ammonium Molybdophosphate, and Its Properties," J. Radioanal. Nucl. Chenz., Articles, 140(1), 15-2 1 (1990).

15. J. L. Collins and J. S. Watson, Economic Evaluation for the Production of Sorbents and Catalysts Derived from Hydrous Titanium Oxide Microspheres Prepared by the HMTA Internal Gelation Process, ORNL/TM-1999/212, Oak Ridge National Laboratory, Oak Ridge, Tenn., April 2000.

16. P. A. Haas, "Gel Processes for Preparing Ceramics and Glasses,” Chem. Eng. Process, 85(4), 44-52 (April 1989).

17. R. K. Iker, The Chemistry of Silica, Wiley, New York, 1979.

18. P. A. Haas et al., Chem. Eng. Process Sympo. Ser., 63, 16, 1967. 
19. H. D. Ringel and E. Zimmer, "The External Gelation of Thorium Process for Preparation of $\mathrm{ThO}_{2}$ and (Th, U) $\mathrm{O}_{2}$ Fuel Kernels," Nucl. Technol. 45, 287-298 (1979).

20. C. J. Brinker et al., eds., Mater. Res. Soc. Symp. Ser. 32, North Holland, New York, 1984. 21. 0. J. Heinonen, J. Lehto, and J. K. Miettinen, "Sorption of Strontium (II) and Radio Strontium Ions on Sodium Titanate," Radiochinz. Acta 28, 93-96 (1981).

22. R. G. Anthony, C. V. Philip, and R. G. Dosch, "Selective Adsorption and Ion Exchange of Metal Cations and Anions with Silica-Titanates and Layered Titanates,"Waste Manage. 13, 503-5 12 (1993).

23. F. W. van der Brugghen, A. J. Noothout, M.E.A. Hermans, J.B.W. Kanji, and 0. Votocek, “A U(VI)-Process for Microspheres Production," Proceedings of the Symposium on Sol-Gel Processes and Reactor Fuel Cycles, Gatlinburg, Tenn., May 4-7, 1970, 253-263, 1970.

24. P. A. Haas, J. M. Begovich, A. D. Ryon, and J. S. Vavruska, "Chemical Flowsheet Conditions for Preparing Urania Spheres by Internal Gelation," I\&EC Product Research \& Development 19(3), 459-467 (September 1980).

25. M. H. Lloyd, J. L. Collins, R. L. Fellows, S. E. Shell, D. H. Newman, and W. B. Stines, $A$ Gel Sphere Process for FBR Fuel Fabrication from Coprocessed Feed, ORNL/TM-83 99, Oak Ridge National Laboratory, Oak Ridge, Tenn., February 1983.

26. J. L. Collins, D. J. Davidson, C. W. Chase, B. Z. Egan, D. D. Ensor, R. M. Bright, and D. C. Glasgow, Development and Testing of Ion Exchangers for Treatment of Liquid Wastes at Oak Ridge National Laboratory, ORNL/TM- 123 15, Oak Ridge National Laboratory, Oak Ridge, Tenn., March 1993.

27. J. L. Collins, B. Z. Egan, K. K. Anderson, C. W. Chase, J. E. Mrocheck, J. T. Bell, and G. E. Jernigan, Evaluation of Selected Ion Exchangersfor the Removal of Cesium from MVST W-25 Supernate, ORNL/TM- 1293 8, Oak Ridge National Laboratory, Oak Ridge, Tenn., April 1995.

28. J. L. Collins, U.S. Patent 582 1186, Method of Preparing Hydrous Titanium Oxide Spherules and Other Gel-Forms Thereof (issued 10/13/1998).

29. J. L. Collins, a U.S. patent application entitled "Method of Preparing Hydrous Zirconium Oxide Gels and Spherules," was submitted to the U.S. Patent Office in October 1999. 
30. J. L. Collins, M. H. Lloyd, and R. L. Fellows, Effects of Process Variables on Reaction Mechanisms Responsible for AD UNHydrolysis, Precipitation, and Gelation in the In ternal Gelation Gel-Sphere Process, ORNL/TM-8818, Oak Ridge National Laboratory, Oak Ridge, Tenn., April 1984.

3 1. J. L. Collins, M. H. Lloyd, and R. L. Fellows, "The Basic Chemistry Involved in the InternalGelation Method of Precipitating Uranium as Determined by pH Measurements," Radiochim. Acta 42, 121-134 (1987).

32. J. R. Polley, C. A. Winkler, and R.V.V. Nicholls, "Studies of the Formation of Hexamine from Formaldehyde and Ammonium Salts in Aqueous Solution," Can. J. Res., Sect. B. 25, 525-534 (1947).

33. J. L. Kassner, H. P. Crammer, and M. A. Ozier, Anal. Chem. 20, 1052 (1948). 
ORNL/TM-2000/367

\section{INTERNAL DISTRIBUTION}

\author{
1. K. K. Anderson \\ 2. C. W. Chase \\ 3-12. J. L. Collins \\ 13. R. D. Hunt \\ 14. R. T. Jubin \\ 15. L. N. Klatt \\ 16. D. D. Lee
}

17. C. P. McGinnis

18. L. E. McNeese

19. R. D. Spence

20. J. S. Watson

21. Central Research Library

22. ORNL Laboratory Records-RC

23-24. ORNL Laboratory Records-OSTI

\section{EXTERNAL DISTRIBUTION}

25. J. J. Duteau, Science Applications International Corporation, EM-53, 555 Quince Orchard Road, Suite 500, Gaithersburg, MD 20878

26. Samuel D. Fink, WestinghouseSavannahRiverCompany,P.O. Box 616, 773-A, RoomB112, Aiken, SC 29808

27. Kurt Gerdes, TFA Headquarters ProgramLead, DOE Office of Science and Technology, 19901 Germantown Road, 1154 CloverleafBuilding, Germantown, MD 20874-1290

28. J. L. Harness, Department of Energy, Oak Ridge Operations, Office of Science and Technology, P.O. Box 2001, Oak Ridge, TN 37831

29. D. Lillian, Department of Energy, Office of Science and Technology, EM-53 CL, 19901 Germantown Road, Germantown, MD 20874

30. J. McGlynn, Science Applications International Corporation, EM-53, 555 Quince Orchard Road, Suite 500, Gaithersburg, MD 20878

3 1. J. R. Noble-Dial, U.S. Department of Energy, Oak Ridge Operations Office, P.O. Box 2001, Oak Ridge, TN 37831

32. Arlin Olson, Idaho National Engineering and Environmental Laboratory, Building 637, MS-5218, Idaho Falls, ID 83415-5218

33. Jim Rindfleisch, Idaho National Engineering and Environmental Laboratory, Building 637, MS-5218, Idaho Falls, ID 83415-5218 
34. I. Tasker, Unitec, 9 East Second Street, Suite 1, Frederick, MD 21701

35. T. R. Thomas, Lockheed Martin Idaho Technologies Company, P.O. Box 1625, MSIN-3458, Idaho Falls, ID 83415-3423

36. M. C. Thompson, Westinghouse Savannah River Company, Savannah River Technology Center, Building 773-A Aiken, SC 29808

37. T. A. Todd, Idaho National Engineering and Environmental Laboratory, Building 637, MS-5218, Idaho Falls, ID 83415-5218

38. J. H. Valentine, Lockheed Martin Idaho Technologies Company, P.O. Box 1625, MSIN-3204, Idaho Falls, ID 83415-3204

39. P. E. Woodall, U.S. Department of Energy, Idaho Operations Office, 750 DOE Place (MS-1 145), Idaho Falls, ID 83402 